\title{
Implementation of Project-Based Learning in Environmental Education
}

\author{
Nurul Ain Zulhaimi, Siti Katijah Johari, Nur Shafiekah Sapan, Siti Aishah Ramliand Siti \\ Nurul Aishah binti Abdul Hamid
}

\begin{abstract}
Environmental education is becoming more important and relevant as we reach the $21^{\text {st }}$ century and the need for sustainable development to protect the earth for the future generation. The lacking of knowledge and awareness of the scarcity of our nature means there is that our natural resources becoming scarce and we are facing all types of environmental consequences. This paper explores the implementation of project-based learning in educating and enhancing ecological awareness among university students. The application of project-based learning in solving and protecting precious earth environmental being discussed and presented. Also, this paper shows the value of the project-based approach by the respondents' reflection. It is proved that project-based learning has helped to nurture a positive attitude towards the environment.
\end{abstract}

Keywords: project-based learning, environmental education: awareness

\section{INTRODUCTION}

We live in the era of the fourth industrial revolution, the period in which we relied on technology as showing the advancement of humanity. Nevertheless, the destruction of the environment is becoming more severe as we are entering a new century. The environmental pollution in any forms proportionally directly related to the modernisation. We are now facing climate change, animals and plants extinction, improper waste of disposal, air pollution, water pollution and so many environmental-related issues. Somehow, the progression to the world did not change our behaviour to the environment. Humans are still self-centred when comes to the protection of the environment. To safeguard our precious environment, people need to realise that our earth in need of defence and we are the ones who can manage the earth properly, as it should be. One of the possible ways that can be done is through education. Education is a powerful tool to make people realise our depleted resources and methods to help appropriately manage our environment. People need to become aware of an ecologically related issue that happening day by day and they need to feel that it is no other than themselves' duty to manage or maybe restore the environment to a better condition.

Nurul Ain Zulhaimi, Centre for the Promotion of Knowledge and Language Learning, Universiti Malaysia Sabah, Labuan, Malaysia

Siti Katijah Johari, Centre for the Promotion of Knowledge and Language Learning, Universiti Malaysia Sabah, Malaysia

Nur Shafiekah Sapan, Centre for the Promotion of Knowledge and Language Learning, Universiti Malaysia Sabah, Malaysia

Siti Aishah Ramli, Centre for the Promotion of Knowledge and Language Learning, Universiti Malaysia Sabah, Malaysia

Siti Nurul Aishah Abd. Hamid, Centre for the Promotion of Knowledge and Language Learning, Universiti Malaysia Sabah, Malaysia
One of the meaningful educational approaches is through project-based learning. Project-based learning can be applied in many subjects that come with many benefits. It is intended to involve students in a real-world problem so that deep learning can occur [1]. Project-based learning also has been proved to help students to understand subjects better compared to the students that are not using project-based learning [2]. It is a student-centred approach where the students are learning by doing [3]. The key features of project-based learning are practical because students are learning by solving the real-world problems and this put theory into practice. Students are required to come with the ideas and solution in the learning process by themselves. This approach train students to be able to plan, execute and learn the impact of their decision by their capability. Students will become empowered because they are now not just learning but can become part of any lesson problems.

The project-based learning also received positive feedback from the teachers as it helps to continuous improvement in their teaching and learning process. Some upgrades, mainly in the aspects of the development of students' competencies, collaboration, and enhancing lecturers' professionalism, can be improved from time to time [4]. The teacher becomes a facilitator in guiding the student to be on the right track without total interference. In other words, the role of the teacher does not become the only contributor to the enhancement of the knowledge, as they become the project manager as well as a mentor to the students. Lesson are expected not to become teacher-approach as they acquire more collaborative work and can be done in an interdisciplinary manner [5]. Putting project-based learning into practice, it is expected to provide many benefits to the course outcome and tremendous effects on the students.

Environmental awareness can be enhanced through adequate knowledge. In this study, project-based learning was applied to enhance student's awareness and empathy towards nature further. Effective learning is not solely dependent on teachers' responsibilities. To make an interesting and more efficient study, students need to involve as active participants in contributing or challenging any ideas. Project-based learning is one the applicable approach that can offer real-world problem to be solved. The objectives of this research are to apply the implementation of project-based learning in an environmental course. Secondly, the project also aims to study the benefits of project-based learning. This paper will present four different environmental-related projects that were proposed by the students. The benefits of project-based learning are also discussed before the conclusion using the student's reflection. 


\section{METHODOLOGY}

Students were divided into a group of four to seven members. The duration of the project is 12 weeks to complete. Every project was monitored or revised every week by the researcher. At the beginning of the lesson, the weekly schedule for the project to be completed in time. It starts with information about the project and group division. After that, students were introduced to project-based learning, and they began to brainstorm the ideas. The ideas were then gathered in a proposal. After the evaluation and changes being made, every group started their projects following what has their initially planned. This paper chose and presented four difference project that has successfully executed. The students' reflection will then discussed. The recommendation to enhance the quality of the students project-based learning is also presented at the end of this paper. Researcher use observation as a method as this paper is still at a preliminary stage.

\section{DISCUSSION}

Every step in project-based learning is crucially important to ensure that the objectives of the project is achieved. Every project needs to be carefully designed due to several limitations that will furtherly discuss in the next section. With this thought in mind, every group has come out with their project that thoroughly supervised by the researcher. In this paper, four different projects are being presented in explaining the students' effort to protect their environment using their ideas and capability.

\section{A. Project I - Plastic Bottle Recycling}

This project started with collecting the recyclables items from the student housing. The duration of the collecting phase is for 6 weeks during the semester. The approach taken for collecting phase is by providing boxes and place under the student housing area. In this project, the aims of the project stated are to encouraged people to do recycling activities and enhancing the knowledge of recycling among the students. This is being done by providing alternatives to simply dispose of the waste especially plastic, cans and paper. This project is proposed after group experience, and observation for the lack of the places to put recyclable items hinder their intention to support collecting recycling items. By preparing accessible places to put their used materials, the student successfully collects many materials each day. It is proved that by providing proper places and prepare many recycle bins near to the students housing, people are willing to send their used materials to dedicated places. Second objectives are achieved by preparing brochure and disseminate to the students. This action can enhance the knowledge of recycling and pursuing green lifestyle among the students Recycling can help to conserve natural resources and can reduce the marine pollution. This is the first step before adopting the non-usage of single-use plastic items towards the eco-friendly lifestyle. Through reflection, the students stated that they learn to reduce their consumption of waste, especially water bottle. Nevertheless, they also mentioned that they felt proud at the end of the project when they send their recyclable items to the recycling centre.

\section{B. Project 2 - Green Campaign - Greenhouse Effects}

Environmental education is becoming more important and relevant as we reach the $21^{\text {st }}$ century. Without proper knowledge of the scarcity of our nature, there will be no action to protect the earth. The group in this project chose greenhouse gas effects as their main topic. They use a campaign platform to disseminate information and awareness about the greenhouses gases. Education about greenhouse gases may not be a concern to the general public but they have contributed to the environmental problem from such a long time. From observation, the leader of the group is the pillar of this group. She is very passionate about the topic and can explain very well about the topic while making it interesting. The leader plays an important role in group work like this project-based learning and the leader of this group seriously play a very excellent role in bringing the group to the direction. Although the campaign just involves the student in the group member institution, the effectiveness of this approach reflects when they take an effort to explain to each individual about the effects of the greenhouses gases. Besides, to personalise individual campaign, they also provide brochure created by their own to the listener. Group members from this project take a further step by promising to reduce their carbon footprint in the future. This project shows that they become fascinated with the topic after they research the topic thoroughly and realise the severity of the greenhouse effects on earth.

\section{Project 3 - Upcycling: Project with the Community}

One of the projects that involved directly with the community was taken by one group by designing an upcycling project. The targeted audience were children from one childcare centre. This project aimed to protect the environment by using less plastic and teach to the younger generation about the concept of upcycling. In this project, the students use their creativity to create something useful from used plastic bottles. Initially, the students explain the concept of upcycling, the benefits, and example of the materials and how to create a new item. Upcycling differs from recycling because upcycling means give used materials to create something useful. This approach can save the environment and at the same time nurture creative skills in an individual. Besides, it also can become the source of income by selling the finished product by saving the cost at the same time since the materials used are originally a waste product. In this project, students involved need to deal with the children centre and obtain permission to proceed with the projects. The roles of every student in the group are important since it involves a third party. During the execution of the project, everyone enjoys learning the concept of upcycling. Through this project, it is believed the support from the community also play a significant role to make sure the objective $s$ is achieved. In this case, the collaboration from the centre is much needed for the continuous environmental-related program in the future.

\section{Project 4 - Animal Extinction}

There are are many animals that are now threatened to become extinct. The International Union for Conservation of Nature's Red List of Threatened Species listed more than 
30,000 species threatened with extinction[12]. Realising the hard reality of facing so much more loss in the future, these group took the initiative to bring forward this topic as their primary concern in their project-based journey. After weeks of discussion and planning, they come out with activities that will primarily be focused on their course mates. Their project, Animal and Us started with a comprehensive campaign about animals condition around the world. They utilise video presentation and a brief explanation about what is happening and what are the steps that we need to do in saving the animals. Some hands-on activity was conducted in the campaign such as quizzes, poster making and presentation involving all the audience. Many participants enjoy the activity so much as they are learning more about the current threatened and endangered species on a personal basis. Using the advance of technology and combined it with creativity and passion, there is no doubt that each one of the students can achieve their objectives. The objectives listed at the beginning of the development of the project os for them to raise awareness about animal extinction and to make the participants more sensible about their daily preferences of life.

\section{BENEFITS IF PROJECT-BASED LEARNING}

It is clear that project-based learning positively influences a student to be more aware of the environmental problem that happens around them. Their feedbacks reflects a realisation that the environment is in critical condition. Almost all the students stated that their involvement in this project make them realise that the severity of the environmental problem. S3 mentioned that "When my group does our project, which is "Save and Reduce", I realise that the earth slowly destroyed because of what we do on this earth. This project also makes me understand that it is essential to reduce our usage of plastic". Meanwhile, S4 stated, "During the project, I increasingly realised that it was crucial to protect the natural environment. Respondent S216 wrote, "Before this project, I have minimal knowledge and very little awareness of the sea. 'Save The Water' project help me out by understanding the ocean system much better. Many students also feel that the project has changed their way of life in viewing the environment. S192, for instance, told that "This project has changed me in many ways. Before this project, I knew the importance of the conservation of our environment but not to the extent as to what I am now. Before this project, I used single-use plastic bags without a second thought. It was a standard process for me; hence, it didn't cause any concern. But after this project, I've realised how important it is to be more mindful of the things I use and waste". It can be summarised that students are becoming more conscious and responsive to the environmental problem that happened after they involved in the project.

Knowledge enhancement and improvement achievement have also been identified as one of the advantages of the project-based learning [2], [6]-[8] Students are exposed to the real-life problem as one of the project-based learning approaches. This method has been used in this course and students reported that they now have better knowledge about the environment in which they learn in this type of active approach. Among the comments are S207, "In the secondary school, the knowledge of environment all comes from books and the internet, and I do not participate in this kind of activities, but now I am glad because I learned many things through this activity", S90, After doing this campaign, I gained more educational knowledge and information since we need to do some studies first before we conduct the campaign. The students realise that they have the power and responsibilities to save the earth and not just depending on specific organisations. Respondent S2 mentioned, "After this project, I realise that the action to save the earth does not depend on the scientist that run much research to save the earth. But it was also our responsibility to protect the earth. S182 promised to buy food using own container, avoid using a plastic straw and not buying a drink with a plastic cup. The objectives of the project-based learning are achieved when student realise that every person has the responsibility to save the environment for the next generations as reflected in many respondents

Project-based learning has proven to develop essential skills such as reported in many works of literature. Among the skills described are teamwork, collaboration, problem-solving skills, communication skills, whether orally or written, time and project management [9], [6], [10]. These skills are imperative for the students for their current and future self as they can be applied in other sections of their life. In this research, there are some skills developed throughout the project. Among them that frequently reported by the students are the improvement in communication skills. The students said that the projects improve their communication skills. Among of their response are, S53 "At first I hesitated to interact with people as I felt a little bit awkward, but luckily I was kind of adopt the situation and start to interact with people and tell them about our campaign". S57 mentioned, "I have been able to improve our teamwork and improve our communication skills". S49 said, "apart from it helps us to enhance our soft skills because we need to approach people to tell them about our project." Besides, S208 also said that "I also learned how to communicate more with other students in UMSKAL, and the workers". S91 even among the students that this approach has also increased their confidence level to speak.

Since the Project-based learning needs to be executed in a group, they also learn to work in groups even though many of them met for the first time in this course. As they mention in the following, collaboration between each group members to make their project successful. The ability to work in a group need to nurture because working in groups need understanding, toleration from each of the group members. Teamwork is critical as they can lead to an increase in their motivation too. Reflection from the students mentioned they are building a strong bonding with group members, acknowledge that cooperation is important, and a better result achieved when working in a group. Besides, many students realise that good teamwork is the key to success as the duration of the project is limited. Many agreed that the project could not succeed if only one person does all the tasks. 
Many respondents are mentioning how the project-based approach taught them about project management and their creativity. Project management is one of the crucial $21^{\text {st }}$-century skills apart from communication and collaboration ability. These sills are very important and aligned with the efforts of the government. Students mentioned. Skills as project management, presentation S58 stated that "Throughout this campaign, I can learn more about how to manage the programme". Also, S174 mentioned, "Besides that, through this project, we can learn to run a project". S49 is mentioning the different of this course compared to other course - "For me, this project is somehow quite good because it lets us experience a new type of coursework. Usually, another assignment would be something related to do some researching for books or internet sources then we will do our course work based on our research. But this project is different because we have to do it as a real-world problem". Also, S90 stated that "Moreover, I gained more experiences on handling project such as where to get information, with whom we should work together, how to manage time wisely and not to forget, how to spread the awareness in the correct ways". The opportunity to work from the scratch of the project let them student explore how to manage a project and improve their organisation skills in the future

\section{CONCLUSION}

Project-based learning is one of effective approach in education and can be apply in many courses. According to the projects presented by the students, it can be concluded that project-based learning has improved students environmental knowledge and awareness. The application of project-based learning in environmental education can cross many areas from air, water, animals, plants, waste and other aspects of environmental concern. The student felt empowered because they realise that they can help the environment and play essential responsibilities towards ecological elements. Advantages of project-based learning also reflected every member involved in the proposed project. After the implementation of the project, the feeling of satisfaction and proud can nurture their motivation to protect the environment in the future. The realisation that every citizen has to protect the earth for our future generation is one of the essential aspects achieve in this research. Besides, by implementing project-based learning approach, we are preparing our students to meet the twenty-first century with meaningful skills and appropriate preparation [11]. These skills are crucial for the students and will not comprehensively learn using the traditional method. It is recommended to apply project-based learning and adapt it to any relevant courses. Teachers and students will undoubtedly amaze and enjoy with the outcome of project-based learning.

\section{REFERENCES}

[1] G. Weichhart and C. Stary, "Project-based learning for complex adaptive enterprise systems," IFAC-PapersOnLine, vol. 50, no. 1, pp. 12991-12996, 2017.
[2] N. R. Ergül and E. K. Kargın, "The Effect of Project based Learning on Students' Science Success,” Procedia - Soc. Behav. Sci., vol. 136, pp. 537-541, 2014.

[3] P. C. Crawford, "Food Waste and Behavior Change rough Project-Based Learning," p. 101, 2015.

[4] J. Lasauskiene and A. Rauduvaite, "Project-Based Learning at University: Teaching Experiences of Lecturers," Procedia - Soc. Behav. Sci., vol. 197, no. February, pp. 788-792, 2015.

[5] M. T. D. Mohedo and A. V. Bújez, "Project based Teaching as a Didactic Strategy for the Learning and Development of Basic Competences in Future Teachers," Procedia - Soc. Behav. Sci., vol. 141, pp. 232-236, 2014

[6] D. Efstratia, "Experiential Education through Project Based Learning," Procedia - Soc. Behav. Sci., vol. 152, pp. 1256-1260, 2014.

[7] M. T. C. Gerhana, M. Mardiyana, and I. Pramudya, "The Effectiveness of Project Based Learning in Trigonometry,” J. Phys. Conf. Ser., vol. 895 , no. 1, 2017

[8] D. Ruggiero and J. D. Boehm, "Project-based learning in a virtual internship programme: A study of the interrelated roles between intern, mentor and client," Comput. Educ., 2017.

[9] F. Alacapinar, "Effectiveness of project-based learning," Egit. Arastirmalari - Eurasian J. Educ. Res., no. 33, pp. 17-34, 2008

[10] J. Rodríguez, A. Laverón-Simavilla, J. M. Del Cura, J. M. Ezquerro, V. Lapuerta, and M. Cordero-Gracia, "Project Based Learning experiences in the space engineering education at Technical University of Madrid," Adv. Sp. Res., 2015.

[11] S. Bell, "Project-Based Learning for the 21st Century: Skills for the Future," Clear. House A J. Educ. Strateg. Issues Ideas, vol. 83, no. 2, pp. 39-43, 2010.

[12] "IUCN List Background \& History," [Online]. Available: https://www.iucnredlist.org/about/background-history.

Nurul Ain Zulhaimi is a lecturer in CPKLL, UMS, Malaysia. Her research interests is solid waste management and environmental education.

Siti Katijah Johari is a lecturer in CPKLL, UMS, Malaysia. Her research interests is English language teaching and learning.

Nur Shafiekah Sapan is a language teacher in CPKLL, UMS, Malaysia. Her research interests is English language teaching and learning.

Siti Aishah Ramli is a language teacher in CPKLL, UMS , Malaysia. Her research interests is English language teaching and learning.

Siti Nurul Aishah Abdul Hamid is a language teacher in CPKLL, UMS, Malaysia. Her research interests is on teaching and learning in Arabic language. 